\title{
INFORMATION SUPPORT OF E-PARTICIPATION OF CITIZENS IN PUBLIC AFFAIRS. ANALYSIS OF THE EXPERIENCES OF THE US AND THE EU MEMBER STATES
}

\begin{abstract}
The article presents three key elements involved in e-participation of citizens in public affairs. Firstly, e-information - information on the government web sites that is of interest to the community. Secondly, e-consultation - mechanisms and tools of online discussion on socially significant problems. Thirdly, e-decision making - the consideration of the contribution of online citizens in the decision-making process, providing continuous feedback. Moreover, the article presents the challenges that rise from implementing them, as well as the benefits that they bring. The most important among these benefits are: strengthening the democratic legitimacy of the authorities, improving the regulations adopted by legislative bodies and decisions made by the executive, more efficient processing of documents and their distribution among the interested parties, and increasing the level of compliance with the established rules.
\end{abstract}

\section{Key words}

e-democracy, e-consultation, e-information, e-decision making

\section{Introduction}

The article presents three key elements involved in e-participation of citizens in public affairs. Firstly, e-information - information on the government web sites that is of interest to the community. Secondly, e-consultation - mechanisms and tools of online discussion on socially significant problems. Thirdly, e-decision making - the consideration of the contribution of online citizens in the decisionmaking process, providing continuous feedback. 